\title{
THE INTERPLAY OF STERIC AND ELECTRONIC FACTORS AFFECTING GEOMETRICAL ISOMERISM OF DIARYL KETIMINE DERIVATIVES
}

\author{
P. A. S. Smith and E. P. Antoniades* \\ Dept. of Chemistry, University of Michigan, Ann Arbor, Michigan
}

(Received 23 July 1959; in revised form 21 January 1960)

\begin{abstract}
The evidence bearing on the mechanism of the Schmidt reaction with ketones is critically reexamined. It is shown that dehydration of an initially formed azidohydrin (I) to a ketiminodiazonium ion (II), which may or may not equilibrate between its geometrically isomeric forms (IIa or b), can account for the various reported ratios of isomeric amides produced from unsymmetrical ketones. The previously anomalous behavior of ortho-substituted diaryl ketones can be resolved by taking into account the influence of conjugative effects on the preferred rotational positions. The ratios of amides produced from a series of o-alkylbenzophenones by both the Schmidt reaction and oximation plus Beckmann rearrangement have been determined at different temperatures; there are appreciable differences in the product ratios and their temperature coefficients from the two reactions.
\end{abstract}

IN 1948 one of us proposed ${ }^{1}$ a mechanism for the Schmidt reaction ${ }^{2}$ between hydrogen azide and ketones, which in the ensuing decade has been the basis for most discussion of the reaction. So much pertinent experimental investigation and theoretical discussion has since been published that a reconsideration of the overall picture seems justified at this time.

The principal reaction products of ketones and hydrogen azide are amides, of which a single compound is produced from symmetrical ketones, but a pair of isomers may be produced in unequal amounts from unsymmetrical ketones. In addition, there have been found, to an extent varying strongly with both structure and reaction conditions, nitriles, 1,5-disubstituted tetrazoles, ureas, and 5-aminotetrazole derivatives; the first of these requires one mole of hydrogen azide, the second two, two moles, and the last requires three moles for formation.

$$
\begin{aligned}
& R-\mathrm{CO}-\mathrm{R}^{\prime}+\mathrm{HN}_{3} \rightarrow \mathrm{R}-\mathrm{NH}-\mathrm{CO}-\mathrm{R}^{\prime} \rightarrow \mathrm{R}-\mathrm{CO}-\mathrm{NH}-\mathrm{R}^{\prime} \\
& \mathrm{R}-\mathrm{CO}-\mathrm{R}^{\prime}-\mathrm{HN}_{3} \rightarrow \mathrm{R}-\mathrm{CN} \\
& \mathrm{R}-\mathrm{CO}-\mathrm{R}^{\prime}+2 \mathrm{HN} \rightarrow \mathrm{R}-\mathrm{N}-\mathrm{C}-\mathrm{R}^{\prime} \div \mathrm{R}-\mathrm{C}-\mathrm{N}-\mathrm{R}^{\prime}
\end{aligned}
$$

- From the doctoral dissertation of E. P. A., University of Michigan, 1957.

1 P. A. S. Smith, J. Amer. Chem. Soc, 70, 320 (1948).

2 H. Wolf, Organic Reactions (R. Adams, Editor-in-Chief), Vol. III. John Wiley, New York (1946). 


$$
R-\mathrm{CO}-\mathrm{R}^{\prime}+2 \mathrm{HN} \rightarrow \mathrm{R}-\mathrm{NH}-\mathrm{CO}-\mathrm{NH}-\mathrm{R}^{\prime}
$$

With the exception of tetrazoles originating from nitriles, the products derived from more than one mole of hydrogen azide cannot be obtained from the compounds whose formation consumed less hydrogen azide, under the conditions used in Schmidt reactions. Reactive intermediates are therefore involved, which under appropriate conditions have the choice of reacting with more hydrogen azide or of reacting in another way to give terminal products.

The mechanism originally referred to ${ }^{1}$ embraces the foregoing essential facts, satisfactorily, as has been developed in subsequent publications. ${ }^{3}$ On the other hand the reason for the observed ratios of isomeric amides from unsymmetrical ketones has been a perplexing problem, which has brought forth successively more drastic modifications of the original proposal. This paper is addressed largely to this aspect of the reaction.

Until recently there has been general acceptance of the view that the Schmidt reaction proceeds by combination of the conjugate acid of the ketone with molecular hydrogen azide to produce a protonated azidohydrin (I), which loses water to form an jminodiazonium ion (II $a$ and $b$ ), capable of assuming two geometrically isomeric configurations when $\mathrm{R}$ and $\mathrm{R}^{\prime}$ are different. The reasonable assumption that rearrangement occurs at this stage by migration of the group anti to the diazonium

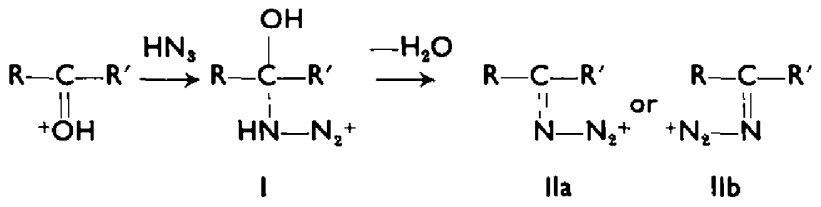

nitrogens provides a means whereby steric factors may influence the isomer ratio of the amides ultimately formed. The relative populations of IIa and IIb as formed

$$
\begin{aligned}
& \mathrm{lla} \rightarrow \mathrm{R}-\mathrm{N}=\stackrel{+}{\mathrm{C}}-\mathrm{R}^{\prime} \stackrel{\mathrm{H}_{2} \mathrm{O}}{\longrightarrow} \mathrm{R}-\mathrm{NH}-\mathrm{CO}-\mathrm{R}^{\prime} \\
& \text { IIIa } \\
& \mathrm{Hb} \rightarrow \mathrm{R}-\stackrel{+}{\mathrm{C}}=\mathrm{N}-\mathrm{R}^{\prime} \stackrel{\mathrm{H}_{2} \mathrm{O}}{\longrightarrow} \mathrm{R}-\mathrm{CO}-\mathrm{NH}-\mathrm{R}^{\prime}
\end{aligned}
$$

IIIb

from the ketone may be presumed to be largely the result of different steric repulsions in the transition states leading to these two configurations, if there is no opportunity for thermodynamic equilibration. The ratio of populations would in turn determine 
the isomer ratio of the rearrangement products, if the rates of rearrangement are appreciably faster than interconversion of the two configurations. ${ }^{*}$

There is an extensive parallel between the ratios of isomeric amides produced in a Schmidt reaction and the equilibrium ratios of geometrically isomeric oximes formed from the same ketones. Furthermore, the ratios of these oxime isomers (usually determined by examination of the amides formed from them by Beckmann rearrangement) are largely in accord with the generalization that the more stable configuration is that in which the bulkier group is anti to the oxime hydroxyl, ${ }^{4}$ and are not influenced by the electronic effects that determine migration aptitudes. ${ }^{5}$ The ratios of amides produced by the Schmidt reaction have been shown to have a similar relation to structure. ${ }^{6}$ To the extent that these generalizations are valid, one can deduce from them that the italicized condition in the foregoing paragraph is satisfied, and that "migration aptitudes" do not therefore determine the isomer ratios in the product.

* The reaction sequence from the protonated azidohydrin, I, to the iminocarbonium ions, IIIa and IIIb, comprises two parallel paths, each of which at constant acidity is a sequence of a pseudo-first-order and a first-order reaction, the first step of which may be reversible, while the second step is irreversible.

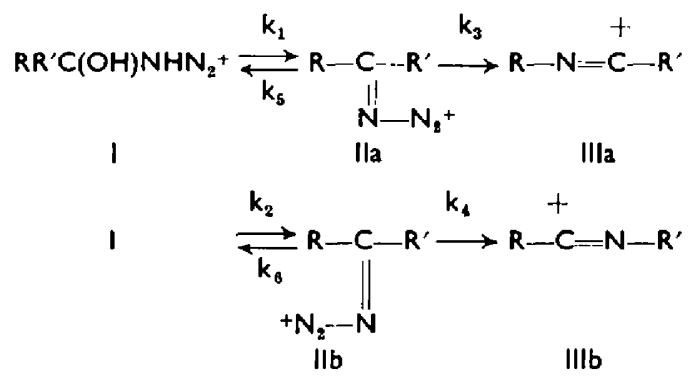

Once IIIa and IIIb are formed, the ratio of isomeric amides derived from them is determined, and we nced not here be concerned with their precise fate. If the first steps are reversible and faster than the second steps, thermodynamic equilibrium between Ila and IIb is attained, and IIa/IIb $=K=k_{1} k_{\mathrm{B}} / k_{2} k_{\mathrm{b}}$. (The same thermodynamic equilibrium might of course be reached by other paths, notably through protonation of II a and IIb to form RR $\stackrel{+}{\mathrm{C}}-\mathbf{N H}-\mathbf{N}_{2}^{+}$, but this would not affect the ratio IIIa/IIIb). It can be shown that in this case the ratio $\mathrm{IHIa/l \textrm {Ib }}$ is given by $K \cdot k_{3} / k_{4}$. The practical result would be that the ratio of amides ultimately obtained would be determined as much by the relative migration aptitudes $\left(k_{3} / k_{4}\right)$ as by the relative stability of geometrical isomers Ila and IIb.

If, on the other hand, IIa and IIb should not interconvert faster than they rearrange, the first steps could be treated as irreversible, and thermodynamic equilibrium would not be attained. The rate expressions in this case are

$$
\begin{aligned}
& \mathrm{d}(\mathrm{II} \mathrm{a}) / \mathrm{dt}=k_{1}(\mathrm{I})-k_{3}(\mathrm{II} \mathrm{a}) \\
& \mathrm{d}(\mathrm{II}) / \mathrm{dt}=k_{2}(\mathrm{I})-k_{4}(\mathrm{IIb}) \\
& \mathrm{d}(\mathrm{IIIa}) / \mathrm{dt}=k_{3}\left(\text { IIa) }=k_{1} \text { (I) } \cdot . \mathrm{d}(\text { II } \mathrm{a}) / \mathrm{dt}\right. \\
& \mathrm{d}(\mathrm{IIIb}) / \mathrm{dt}=k_{4}(I \mathrm{Ib})=k_{2}(\mathrm{I})-\mathrm{d}(\mathrm{IIb}) / \mathrm{dt} \text {. }
\end{aligned}
$$

By dividing the integrated forms of the latter two we obtain the time-dependent expression

$$
\frac{(I I I a)}{(I I I b},=\frac{k_{2}}{k_{2}} \int \frac{(I) \mathrm{dt}-(\mathrm{II})}{(\mathrm{I}) \mathrm{dt}-(\mathrm{IIb})}
$$

for the ratio of the products. It follows readily that the limiting ratio for $t=\infty$ is $k_{1} / k_{2}$, and by the successive application of l'Hospital's rulc the limiting ratıo for $t=00$ is found to be $k_{1} k_{8} / k_{2} k_{4}$. If the transition states for the first steps (dehydration) resemble the products appreciably, $k_{1}$ and $k_{2}$ would be approximately proportional to the thermodynamic stabilities of II a and IIb, and the factors governing the relative stability of the geometrical isomers would operate to determine the ratio of amides obtained, and a parallel hetwcen the Schmidt reaction ratios and oximation ratios would be expected, in agreement with the results generally observed. The parallel would be expected to be only approximate, however, since thermodynamically controlled ratios in oximation are being compared with kinetically determined ones in the Schmidt reaction.

A. D. McLaren and K. E. Schachat, J. Org. Chem. 14, 254 (1949).

W. E. Bachmann and M. X. Barton, J. Org. Chem. 3, 300 (1938).

a P. A. S. Smith and J. P. Horwitz, J. Amer. Chem. Soc. 72, 3718 (1950); ${ }^{\circ}$ H. Schechter and J. C. Kirk. Ibid. 73, 3087 (1951); 'R Fusco and S. Rossi, Gazz. Chim. Ital. 81, 511 (1951); " R. T. Conley, Chem. \& Ind. 438 (1958). 
They also support the contention that the ratio of syn and anti configurations of the iminodiazonium ion (II) is roughly proportional to their relative stabilities, even though the ratio may be kinetically determined.? That is, the two transition states for dehydration of I to IIa and IIb resemble the products, and their relative energies may be approximated by those of IIa and IIb.

The most bothersome exceptions to these generalizations have been observed among benzophenones. Many benzophenones substituted in an ortho position ${ }^{9}$ give ratios of amides and oxime ratios that imply that the more stable configuration has the ortho-substituted phenyl group syn to the $\mathrm{N}$-attached hydroxyl or diazonium group. In another case, $p$-methoxybenzophenone, the usually ineffective migration aptitudes appear to operate to a limited extent in the Schmidt reaction, although they do not in $p$-methoxy- $p^{\prime}$-nitrobenzophenone. ${ }^{6 a, 10}$ Finally, a few benzophenones appear to give ratios of amides from the Schmidt reaction that are measurably different from those of the equilibrated oximes. ${ }^{9 c}$

An attempt was recently made by Arcus, Coombs and Evans ${ }^{11}$ to resolve these anomalies by postulating a substantially different path for the Schmidt reaction, not involving dehydration of $\mathrm{I}$ to an iminodiazonium ion (II). Their proposal features a four-membered chelate ring that undergoes rearrangement entirely intramolecularly to give the conjugate acid of an amide directly. Geometrical isomerism would be possible in this ring intermediate if the bonds about the ring nitrogen have a pyramidal arrangement, and this is presumed to account for the ratios of product isomers.

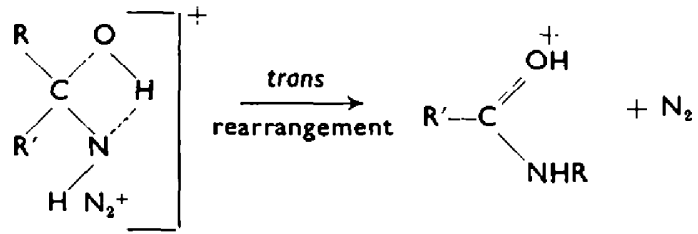

We do not believe this proposal offers a more satisfactory explanation of the observed amide ratios, inasmuch as the attractive and repulsive effects that determine configuration operate between the same groups in the chelate ring intermediate as in the iminodiazonium ion (or the transition states leading to it). Apart from this, however, there are other objections to this intermediate. It is unlikely that such a ring intermediate could satisfy the condition that equilibration between its geometrical isomers be slow, since the energy of the hydrogen bond that completes the ring must be extremely small at the strained angle of a four-membered ring. Furthermore, such an intermediate provides no path for the formation of the other products, such as tetrazoles, sometimes produced in Schmidt reactions, and destroys the mechanistic similarity between the Schmidt reaction and the Beckmann rearrangement.

Experimental support for the ring intermediate has been offered in the form of a Schmidt reaction on fluorenone in which the reaction mixture was worked up by first being poured into methanol; phenanthridone was formed as usual, and no

'That the dehydration step (and its reverse) is probably a slow one is suggested by Jencks' observations that in the analogous oximation process, the carbonyl-hydroxylamine adduct is formed rapidly, but dehydrates to the oxime slowly. ${ }^{8}$

\&. P. Jencks, J. Amer. Chem. Soc. 81, 475 (1959).

9 a G. M. Badger, R. T. Howard and A. Simons, J. Chem. Soc. 2849 (1952); J. R. Dice and P. A. S. Smith, J.Org. Chem. 14, 179 (1949), ' P. A. S. Smith, J. Amer. Chem. Soc. 76, 43! (1954).

10 P. A. S. Smith and B. Ashby, J. Amer. Chem. Soc. 72, 2503 (1950).

11 C. L, Arcus M. M. Coombs and J. V. Evans, J. Chem. Soc. 1498 (1956). 
9-methoxyphenanthridine was detected. It was argued that the concentrated sulfuric acid constituting the reaction medium would "be unlikely to liberate the water" required to convert iminocarbonium ions (III) to amides, and that their procedure should therefore have produced 9-methoxy-phenanthridine if the mechanism actually involved the formation of an iminocarbonium ion. Since only phenanthridone was produced, they concluded that neither iminocarbonium ions nor their necessary precursors, iminodiazonium ions, are formed during thi Schmidt reaction. We believe these arguments to be invalid.

The successful substitution of alcohols for water as the nucleophile taken up by the reactive intermediate in the Schmidt reaction has been known for a long time from the work of Schmidt and others, ${ }^{12}$ who prepared imino esters by treating ketones with hydrogen azide and hydrogen chloride in alcohol solution (9-methoxy-phenanthridine is but a special example of an imino ester). The difference between these experiments and those of Arcus et al. is that the earlier Schmidt reactions took place in the presence of alcohols, while alcohol was not introduced by Arcus et al. until the Schmidt reaction was completed. The latter circumstances allowed the iminocarbonium ion to acquire the elements of water from the environment, presumably by initial reaction with bisulfate ion, notwithstanding the fact that this was nearly 100 per cent sulfuric acid. The ability of iminocarbonium ions to extract water from concentrated sulfuric acid is demonstrated by the well known general procedure for hydrating nitriles to amides by simply warming them with sulfuric acid. Furthermore, if the iminocarbonium ion were thermodynamically incapable of abstracting water from sulfuric acid, we might expect that amides would be dehydrated by that reagent, in contrast to their known stability in sulfuric acid solutions. In addition, Newman and Deno attempted to obtain cryoscopic evidence for the formation of iminocarbonium ions from amides of favorable structure, but failed. ${ }^{13}$ The evidence, then, is definitey contradictory to the chelate ring intermediate, and is consistent with the formation of an iminocarbonium ion; we thus find ourselves returned to the mechanism proposed in 1948.

In order to seek insight into the reasons for the anomalous isomer ratios of the amides from $o$-substituted benzophenones, we began our investigations with a careful repetition of the Schmidt reaction and of the oximation of $o$-methylbenzophenone. We at first hoped to be able to prepare pure samples of the syn and anti oximes of a series of $o$-alkyl benzophenones and to determine their respective absolute entropies by heat capacity measurements from room temperature down to liquid helium temperatures. The preparation of one isomer of $o$-methylbenzophenone by oximation under but mildly basic conditions, of the other by oximation in hot, strong alkali has been reported by Smith. ${ }^{14}$ Similar observations have been reported for 1-benzoylnaphthalene by Betti and Poccianti. ${ }^{15}$ Repeated attempts to confirm these reports failed in our hands, and we believe that the earlier workers may have been misled by samples of different purity, or may have mistaken a eutectic mixture for a single isomer. Attempts to separate the isomeric oximes from the equilibrium mixtures by fractional crystallization or by chromatography gave only the major isomers in pure form.

12 e.g., K. F. Schmidt and P. Zutavern, U.S. Pat. 1,889,323; Chem. Abstr. 27, 1361 (1933).

13 M. S. Newman and N. C. Deno, J. Amer. Chem. Soc. 73, 3651 (1951).

14 A. W. Smith, Ber. Disch. Chem. Ges. 24, 4047 (1891).

15 M. Betti and P. Poccianti, Gazz. Chim. Ital. 45 II, 224 (1915). 
Our next approach, after we found we could not obtain the pure isomeric oximes in this series, was to determine the ratios of oxime isomers formed at two temperatures, $60^{\circ}$ and $118^{\circ}$, in order to estimate from them the magnitude and sign of the differences between the thermodynamic properties of the isomers. The ratios were determined by carrying out Beckmann rearrangements on the mixtures and analyzing the resulting mixtures of amides by infrared spectroscopy.

The results are given in Table 1. It can be seen that an increase of temperature favors the minor isomer, but that the magnitude of the effect varies with the nature of the alkyl group in $o$-alkyl benzophenones. The low precision of measuring the ratios when they are so far from $1: 1$ unfortunately prevents the calculation of reliable thermodynamic constants from them. These data do show the importance of the temperature variable, which must be taken into account when attempting to interpret ratios reported by different investigators; temperatures used in oximation or the Beckmann rearrangement are seldom reported or carefully controlled. Similar temperature effects in the Schmidt reaction on other ketones have been reported by Schechter and Kirk. ${ }^{6 b}$

Table 1 also includes the ratios of amides produced by the Schmidt reaction, carried out at $60^{\circ}$ to allow comparison with the oximation ratios. While these results

TABle 1. ISOMER RATIOS From OXIMATION AND FROM THE SCHMIDT REACTION OF KETONES Ar-CO- $\mathrm{C}_{6} \mathrm{H}_{6}$

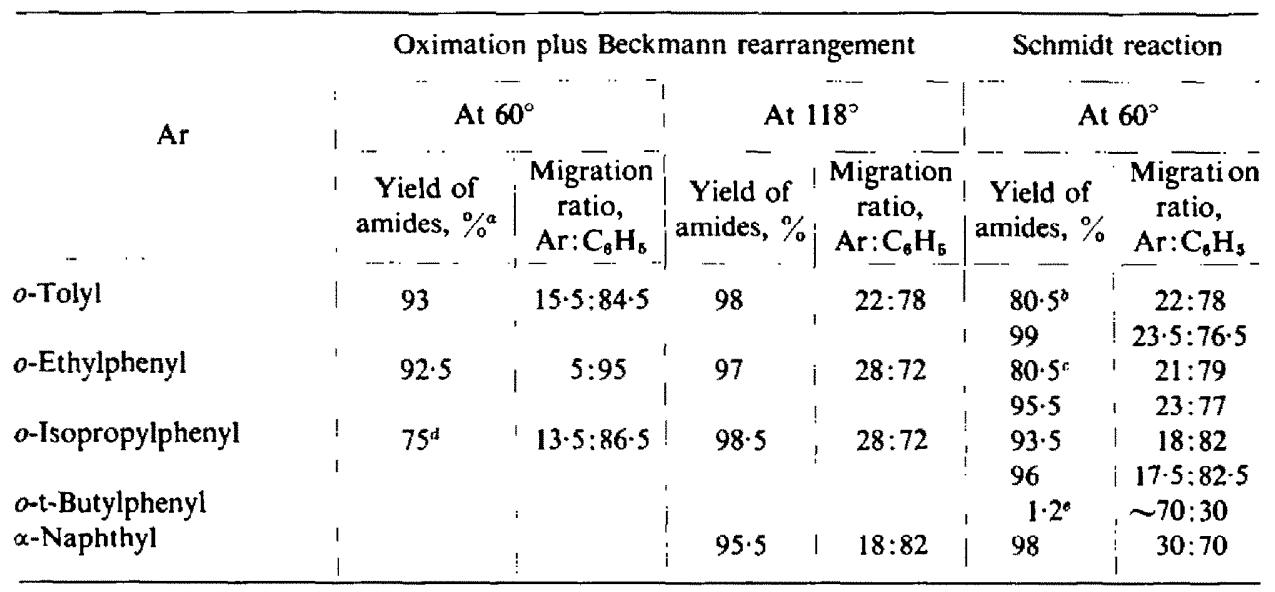

a Overall yield from ketone by oximation followed by Beckmann rearrangement. ${ }^{b}$ Plus $13 \%$ recovery of ketone. c Plus $16 \%$ recovery of ketone. ${ }^{d}$ Plus $20 \%$ recovery of ketone. - Plus $95.5 \%$ recovery of ketone.

support the generalization that the Schmidt reaction and oximation plus Beckmann rearrangement give similar ratios of isomeric amides, they also show that the agreement is only qualitative. There are small but significant differences; furthermore, the direction of the differences depends on the temperature of oximation chosen for comparison, and a temperature must therefore occur in the relatively short range of $60-118^{\circ}$ where the oximation ratios would be essentially the same as the amide ratios from the Schimdt reaction at $60^{\circ}$. Differences of this magnitude are thus so strongly influenced by the various temperature coefficients that a simple interpretation of them in terms of temperature-invariant steric and electronic repulsions would be naive. 
A feature of significance is that there is very little difference in the isomer ratios of the products whether the $o$-alkyl substitutent is methyl, ethyl or isopropyl. (t-Butyl is questionable, since $o$-t-butylbenzophenone was found to be so extremely unreactive that no oximation could be detected, and Schmidt reaction occurred to only a minute extent, even under forcing conditions.) This insensitivity to the size of the ortho substitutent is also found in the $o$-halobenzophenones, which give almost the same ratios of amides by the Schmidt reaction as do the $o$-alkylbenzophenones.

There appear to be two ways by which the near-constancy in the isomer ratios of amides obtained from $o$-alkyl and $o$-halo benzophenones by the Schmidt or Beckmann reactions may be accounted for. The absence of appreciable influence of migration aptitudes and the general stereospecificity with respect to oxime configuration make it reasonably certain that we have to deal with the geometrical isomerism of ketimine derivatives rather than the rearrangement step.* One possibility that the effects due to changes in the size of the ortho-substitutent are balanced by differences in their electronic influence. Such an explanation requires a coincidence in the balance of the two effects that is highly improbable, expecially in view of the known difference of electronic character between halgens and alkyl groups of comparable size. The other possibility is that any substitutent appreciably larger than hydrogen might be sufficient to enforce the observed preferred configuration, and that further increases in size would be without appreciable effect, unless a threshold size should be reached where additional configurational changes are imposed. Such a set of circumstances would

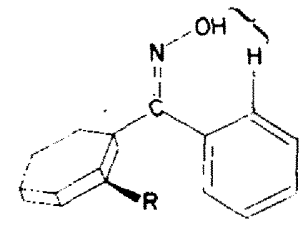

(a)

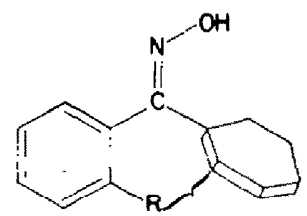

(c)

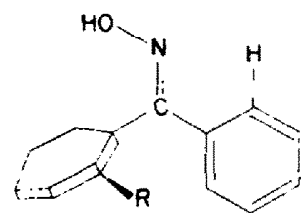

(b)

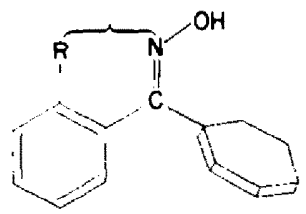

(d)

FIG. 1. Interference in some rotational conformations of ortho substituted benzophenone oximes.

* The discussion of the conformation of the ground states of the geometrical isomers of oximes or analogs may raise the question of their relation to the transition state for rearrangement. If the transition state is properly represented by a bridged structure, $\mathrm{R}-\mathrm{C}=\mathrm{N}-\mathrm{T}$, it would be expected to be of lowest $\mathrm{R}$

energy, in the case of a migrating aryl group, when the plane of the benzene ring is perpendicular to the $\mathrm{C}-\mathrm{N}$ axis. The conformations represented by $\mathrm{B}, \mathrm{C}$ and $\mathrm{D}$ in Fig. 1 would thus have to undergo rotation of the anti- arylgroup as the transition state is approached, incidentally destroying the conjugation that stabilized the ground-state conformation. However, strict perpendicularity is by no means essential, as demonstrated by the readily successful Beckmann and Schmidt reactions of fluorenone, where a large departure from coplanarity would be resisted by the ring structure. The presence or absence of rotation accompanying rearrangement might be reflected in the activation energies, but would not affect the argument given here. 
not be unreasonable if the effect of the substitutent should be to prevent rotation or coplanarity in a critical part of the system.

Scale models of benzophenone derivatives show that an ortho-substituent hinders the substituted ring from being coplanar with an oxime function [or the iminodiazonium intermediate (II)]. This in turn interferes with the substituted ring being in conjugation with the carbonyl derivative ${ }^{16}$ with the result that the favored configuration would be that shown (for oximes) in Fig. 1B, in which the two benzene rings have their perpendicular axes skew to each other, and only the unsubstituted ring is in conjugation. In the case of an oxime or iminodiazonium ion, such a rotational position disposes the carbonyl derivative to have its more stable configuration anti to the unsubstituted phenyl group, owing to interference between the hydrogen in the outer, up-ended ortho position and the hydroxyl or diazo group on the nitrogen.

The effects just delineated consider the ortho-substituent solely as a source of steric hindrance. If, in addition, the substituent is of such electronic character as to promote conjugation, then a conflicting influence is present. Configuration D. (Fig. 1), which allows the ortho-substituted phenyl group to be in conjugation with the $\mathrm{C}=-=\mathrm{N}$ system with the smallest amount of interference, is the geometrical isomer opposite to that in configuration $\mathrm{B}$. The resulting equilibrium would be a balance between the simple bulk effect, leading to the syn-configuration, and the promotion of conjugation, leading to the anti configuration. Such a situation may be met in $o$-methoxybenzophenone, which has been shown to produce roughly equal amounts of the two isomeric amides formed in the Schmidt reaction, and we are thus able to account for the different effect on the isomer ratios of $o$-ethyl and $o$-methoxy, whose steric requirements are not very different.*

An ortho or para methoxy group causes another effect through its electronic influence. Hauser and Vermillion ${ }^{17}$ have described a study of the influence of substituents on the interconversion of stereoisomeric benzaldoximes, and have shown that the methoxy group promotes it. In view of this, it is not unreasonable to expect that the rate of interconversion of the stereoisomers of methoxybenzophenone derivatives might become comparable to the rate of rearrangement, thus allowing migration aptitudes to make their influence felt (cf. paragraph 5). Support for this view in the particular case of $o$-methoxybenzophenone is found in the report that although its two isomeric oximes can be separated, one isomer is considerably more stable than the other. Interconversion occurs under unusually mild conditions. Beckmann rearrangement of either isomer gives principally benzo-o-anisidide. ${ }^{18}$ Since the amides from the Schmidt reaction consist of 50 per cent of this isomer, we see that in both the Beckmann and Schmidt rearrangements migration of the $o$-anisyl group occurs to a very substantially larger extent than of $o$-alkyl- or $o$-halophenyl. Although we cannot from these facts alone tell whether this is the result of the steric effect as influenced by conjugation or of the partial operation of migration aptitudes, a combination of both seems most likely.

It is fruitful in this connection to re-evaluate the observations reported for $p$ methoxybenzophenones, in which the steric effect of an ortho substituent is missing,

* The methoxyl group actually has somewhat smaller steric requirements than the ethyl group, since the effective radius of ether oxygen is less than that of methylene.

18 H. H. Szmant and C. M. Harmuth, J. Amer. Chem. Soc. 81, 962 (1959); R. N. Jones, Ibid. 67, 2141 (1945). 17 C. R. Hauser and G. Vermillion, J. Amer. Chem. Soc. 63, 1224 (1941).

18 a P. Billon, Ann. Chim. [10], 7, 341 (1927); ' M. Martynoff, Ibid. [11], 7, 424 (1937). 
but the electronic influence and migration aptitude are retained. $p$-Methoxybenzophenone should show equal extents of phenyl and $p$-anisyl migration in the Schmidt reaction if only simple steric effects operate. Nevertheless, it has been reported ${ }^{6 a}$ and independently substantiated ${ }^{19}$ that migration of the $p$-anisyl group occurs preferentially to the extent of nearly $2: 1$. This can be interpreted as evidence that migration aptitudes have come into play. There are, however, two other $p$-methoxybenzophenones whose Schmidt reactions have been studied; they are the $p^{\prime}$-chloro and $p^{\prime}$-nitro derivatives. The addition of either of these substituents returns the ratio of migration to the statistical value, $1: 1$, and thus eliminates the effect observed in $p$-methoxybenzophenone. This result is understandable in the light of the work of Chapman and Fidler ${ }^{20}$ on the relative rates of migration of substituted phenyl groups in the Beckmann rearrangement of benzophenone oximes, in which they showed that electron-withdrawing substituents on the non-migrating phenyl group noticeably decrease the rate of rearrangement of the other group. It is also to be presumed that such substituents would decrease the rate of equilibration between the syn-and anti forms of the iminodiazonium ion, analogous to the effect observed by Hauser and Vermillion of these substituents on the interconversion of benzaldoxime isomers. In both ways, therefore, the marginal operation of migrational apitudes in $p$-methoxybenzophenone would be nullified. Evidence that the preferential anisyl migration is at least partly a result of geometrical orientation appears in the characteristics of the

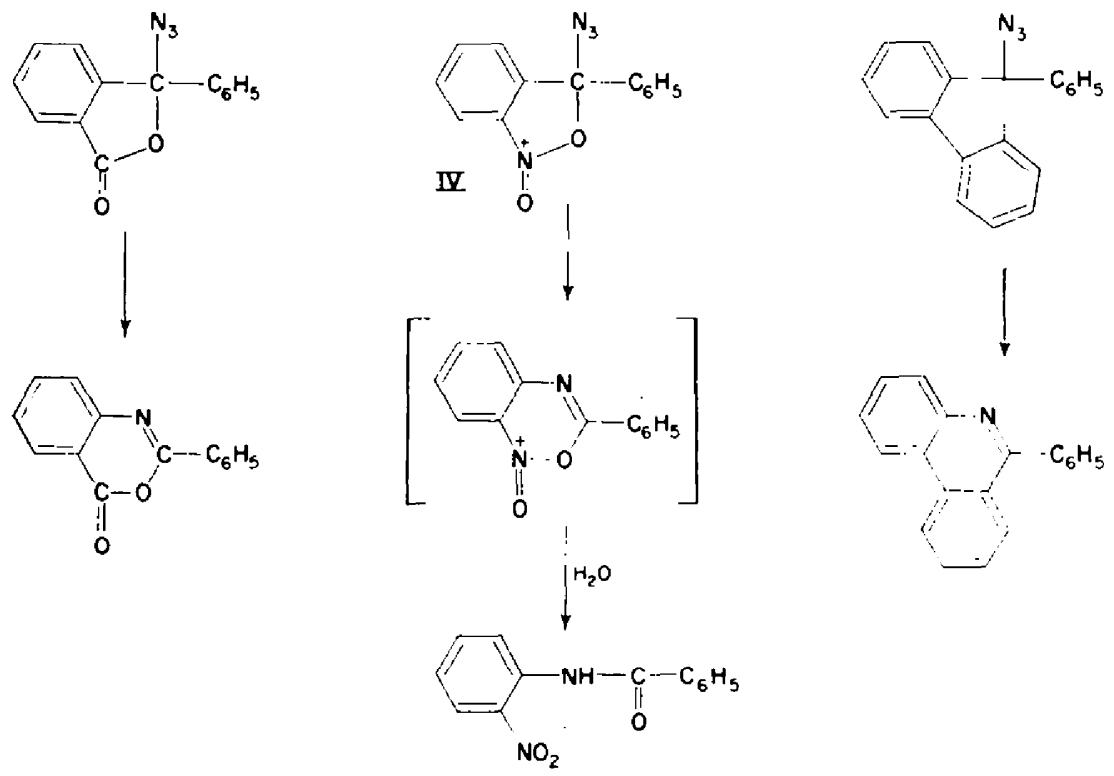

two $p$-methoxybenzophenone oximes. The anti-anisyl isomer, which gives benzaniside on rearrangement, is the more stable. ${ }^{21}$ This is to be expected if the $p$-methoxy group should greatly stabilize a configuration analogous to Fig. 1D, by enhancing conjugation of the anisyl group with the $\mathrm{C}=-\mathrm{N}$ system.

There remains to be discussed a group of three ortho-substituted benzophenones,

19 R. D. Westland and W. E. McEwen, J. Amer. Chem. Soc. 74, 6141 (1952).

20 A. W. Chapman and F. A. Fidler, J. Chem. Soc. 448 (1936).

21 A. Hantasch, Ber. Disch. Chem. Ges. 24, 51 (1893). 
$o$-carboxy, $o$-nitro and $o$-phenyl, which show predominant migration of the substituted aryl group in the Schmidt reaction. The way in which this anomalous behavior can be reconciled has been pointed out by Arcus and Coombs for the first example; cyclization occurs to give a derivative of the lactol form and the rearrangement is that of an azide rather than of a ketimine derivative. ${ }^{*}$ Since the nitro group and the carboxylate ion are isoelectronic, analogous behavior with $o$-nitrobenzophenone might not be unreasonable. $\dagger$ Evidence that such interaction occurs between nitro oxygen and the carbonyl group in $o$-nitrobenzoyl chloride has been given by Szmant and Harmuth. ${ }^{16}$ The analogous behavior with o-phenylbenzophenone would lead to 9-phenyl-9. fluorenyl azide as the intermediate. The necessary postulate that this rearranges to 9-phenylphenanthridine, the observed product of the Schmidt reaction, receives strong support from the report that 9-methyl- and 9-benzyl-9-fluorenol rearrange to the 9-substituted phenanthridines through their 9-azido derivatives.

Since we have seen that the effects which once seemed anomalous in the Schmidt reaction and in oxime configuration of $o$-substituted benzophenones can be understood when the non-coplanarity of the two benzene rings is taken into account, it is especially pertinent to consider the behavior of the related derivatives of fluorenone, in which a bridged structure holds the benzene rings coplanar. Thus geometrical factors should operate in fluorenone derivatives in a way conditioned by the enforced coplanarity of the nuclear system and the $=\mathrm{N}-\mathrm{O}-$ or $=\mathrm{N}-\mathrm{N}_{2}{ }^{+}$in the carbonyl-derived function, distinct from the superficially similar benzophenone system. 1-Substituted fluorenones, the analogues of $o$-substituted benzophenones, are difficult to synthesize and consequently have been little investigated. An example of the oximation and Beckmann rearrangement of such a structure has been reported in the case of retene ketoxime, ${ }^{22}$ which on rearrangement gave solely 2-methyl-8-isopropylphenanthridone. The only example of a Schmidt reaction on a 1-substituted fluorenone is that of 1,3-dimethyl-2-azafluorenone, ${ }^{23}$ which gives 1,3-dimethyl-2-azaphenanthridone, the product formed by migration of the substituted side. It appears from these two examples that the rule of migration of the bulkiest group holds once more in an uncomplicated manner when the conformational effects which have been discussed for benzophenones are prevented by enforced coplanarity.

The behavior of 2- and 3-substituted fluorenones in the Schmidt reaction has been investigated recently, and the results have been presented as further examples of anomalies not explainable by the "greatest bulk" rule for predicting the isomeric

* An alternative explanation has been offered by M. V. Bhatt, Chem. \& Ind. 1390 (1956), utilizing the assumption that an o-carboxyphenyl group would migrate preferentially to phenyl owing to the operation of the "greatest bulk" rule in the stereochemistry of the iminodiazonium ion. Apart from the fact that a mass of data shows that this rule cannot be so simply applied in benzophenone derivatives, it has been shown by C. L. Arcus and R. E. Marks, J. Chem. Soc. 1627 (1956), that $o$-carboxyphenyl also migrates preferentially over the presumably bulkier mesityl group, and the basis for Bhatt's explanation loses its support.

$\dagger$ Support for this is provided by our observation that solutions of o-nitrobenzophenone in sulfuric acid are initially pale yellow (owing to end-absorption of the protonated carbonyl structure), but slowly change their ultraviolet and visible spectral characteristics, becoming rosy-purple with strong blue fluorescence; similar solutions of p-nitrobenzophenone remain unchanged indefinitely. Dr. N. C. Deno and Mr. G. Saines of Pennsylvania State University have kindly determined the van't Hoff $i$-factor in sulfuric acid for us; it has the value 1.9730 min after mixing, corresponding to simple protonation of the carbonyl group, but increases to 3.00 after $70 \mathrm{~min}$ and 5.90 after 2 days (formation of the dipositive ion that would be parent to the azide structure IV would give a theoretical i-factor of 5). It should be noted that the Schmidt reaction on $o$-nitrobenzophenone is very slow- even at $60^{\circ}$, so that ample time is available for the foregoing processes.

2.2 D. E. Adelson and M. T. Bogert, J. Amer. Chem. Soc. 58, 2236 (1936).

23 V. A. Petrow, J. Chem. Soc. 200 (1946). 
constitution of the products. Specifically it was determined that 2-nitrofluorenone produces 2-nitrophenanthridone, the isomer resulting from migration of the nitrated ring to nitrogen, in a ratio of $19: 1 ; 2$-methoxy- and 3-nitrofluorenone gave roughly equal quantities of the respective isomeric phenanthridones (the actual ratio, $69: 31$, reported for 3-nitrofluorenone, should be taken with reservation, inasmuch as it is based on only a 65 per cent yield of amides with no compensating recovery of ketone, and an analytical procedure beset with considerable uncertainties). The oximation of 2- and 3-nitrofluorenones has also been studied, but the results, contrary to the original report, do not allow a reliable estimate to be made of the ratios of isomers formed. ${ }^{24}$ We believe the ratios observed in the Schmidt reaction in reality provide support for the "greatest bulk" rule, by which we will show they too, can be explained.

It has been pointed out (Fig. 1A) that there is interference between the oximino group (and by implication, an iminodiazonium group) and an ortho-hydrogen, when a syn-phenyl group of a benzophenone derivative is coplanar with the carbonyl-derived group. Any fluorenone oxime thus represents a slightly strained system, as a result of the enforced coplanarity, and this strain is presumably accommodated in part by a slight bending of the 1-hydrogen away from the ketoxime group. Now let us consider 2-substituted fluorenones, and particularly 2-nitrofluorenone. The ability of the molecule to accommodate the strain in the syn-oxime by a bending of the 1-hydrogen in the direction of the 2-position will be reduced by the bulk of any 2-substituent. This is the "buttressing effect"25 observed in the mutarotation of optically active biphenyls. The nitro group is particularly bulky, and its bulk gives maximum buttressing effectiveness when it is coplanar with the benzene ring, the position of most effective conjugation. In this position molecular models actually show a small amount of interference between the nitro oxygen and the 1-hydrogen. The result is that the syn-configuration of 2-nitrofluorenone oxime should be noticeably less stable than the anti-configuration, and by implication the Schmidt reaction should reflect these influences by producing mostly the anti-configuration of the intermediate iminodiazonium ion, and from it 2-nitrophenanthridone, the major observed product. Whether a secondary buttressing effect from the 3-nitro group could be sufficiently important to affect the ratio of products from 3-nitrofluorenone is questionable.

While this paper is primarily concerned with aromatic ketones, it is necessary to consider the behavior of aliphatic ketones as well, particularly with regard to the recent report ${ }^{26}$ that there is both a small intermolecular and intramolecular isotope effect with acetone-1 $\mathrm{C}^{14}$. The generally good agreement with the rule of migration of the bulkier group in either the Schmidt reaction or oximation plus Beckmann rearrangement had led to an earlier conclusion that geometrical effects operated in an uncomplicated way. However, it has recently been shown that increasing alkyl substitution at the $\alpha$-carbon increases migration aptitudes (or more precisely, rate of migration) in both $\mathrm{C}$-to-O and $\mathrm{C}$-to-C migrations, ${ }^{27.28}$ which suggests that migration aptitudes might equally well explain the observed products in the C-to- $\mathrm{N}$ rearrangements. It is significant in this connection that isomeric oximes of wholly aliphatic

\footnotetext{
${ }^{24}$ A. J. Nunn, K. Schoefield and R. S. Theobald, J. Chem. Soc. 2797 (1952); K. Schoefield, private communication.

${ }_{25}$ W. F. Forbes and W. A. Mueller, J. Amer. Chem. Soc. 79, 6495 (1957) for a summary of literature.

ss A. Ropp, W. A. Bonner, M. T. Clark and V. F. Raaen, J. Amer. Chem. Soc. 76, 1710 (1954).

${ }_{27}$ M. F. Hawthorne and W. D. Emmons, J. Amer. Chem. Soc. 80, 6393 (1958).

28 R. M. Stiles and R. Mayer, J. Amer. Chem. Soc. 81, 1497 (1959).
} 
ketones cannot usually be isolated, and the behavior when separation is attempted suggests extremely easy interconversion. The same factors which are responsible for this ease of interconversion of oxime isomers should also promote interconversion of the corresponding imindiazonium ion isomers, II a and b, in the Schmidt reaction. As we have already pointed out, as interconversion of the geometrical isomers of the rearranging species becomes important, so does the role of migration aptitudes in determining product ratios.* The isotope effect observed by Ropp et al. implies that in aliphatic ketones migration aptitudes compete with simple geometrical factors in determining the product composition, and the rule of migration of the bulkier group should not necessarily be expected to hold for those aliphatic ketones where migration aptitudes and steric effects may be opposed.

We should like to comment on another factor influencing product ratios in the Schmidt reaction, that of reaction medium. McEwen et al. ${ }^{29}$ studied the effect of the acidity of the reaction medium on the Schmidt reaction on five benzaldehydes (Table 2), and confirmed the original claim by Schmidt ${ }^{30}$ that in the case of benzaldehyde, a

Table 2. Products from the schmidt reaction ON BENZALDEHYDES $p-\mathrm{R}-\mathrm{C}_{6} \mathrm{H}_{4} \mathrm{CHO}$

(According to McEwen et al. ${ }^{29}$ )

\begin{tabular}{|c|c|c|c|}
\hline \multirow{2}{*}{$\begin{array}{l}\text { Substituent, } \\
\text { R- }\end{array}$} & \multirow{2}{*}{$\begin{array}{l}\text { Ratio of } \\
\text { sulphuric acid } \\
\text { to aldehyde }\end{array}$} & \multicolumn{2}{|c|}{ Yield, $\%$} \\
\hline & & i Nitrile & Formanilide \\
\hline \multirow[t]{2}{*}{$\mathrm{H}-$} & 0.72 & 32 & 14 \\
\hline & $5 \cdot 4$ & 10 & 59 \\
\hline \multirow[t]{2}{*}{$\mathrm{CH}_{3} \mathrm{O}-$} & 0.72 & 86 & 0 \\
\hline & $5 \cdot 4$ & 64 & 0 \\
\hline \multirow[t]{2}{*}{$\mathrm{Cl}-$} & 0.72 & 55 & 12 \\
\hline & 5.4 & 15 & 48 \\
\hline \multirow[t]{2}{*}{$\mathrm{NO}_{2}-$} & 0.72 & 72 & 2 \\
\hline & $5 \cdot 4$ & 46 & 23 \\
\hline \multirow[t]{2}{*}{$\mathrm{CH}_{3}-$} & 0.72 & 50 & 6 \\
\hline & $5 \cdot 4$ & 13 & 43 \\
\hline
\end{tabular}

- Yields are based on aldehyde consumed, and include all derived substances.

low ratio of sulfuric acid to aldehyde gave principally benzonitrile, while increasing acidity promoted the formation of formanilide. They interpreted this behavior on the basis of the assumption that benzonitriles arose through elimination in the anti-H configuration of the iminodiazonium intermediate, and that formanilides arose through aryl migration in the syn- $\mathrm{H}$ configuration. In order to account for their results in these terms, they were led to the assumption that the less stable anti- $\mathrm{H}$ configuration was formed first, i.e., more rapidly than the $s y n-\mathrm{H}$ configuration. This assumption is directly opposed to the generalization proposed at the beginning of this paper, and this opposition must be resolved if we are to have a satisfactory overall concept of the operation of the Schmidt reaction.

Reference to the analogous behavior of benzaldoximes does not support the assumption that the anti-isomer is formed first in the Schmidt reaction, but adds strong

- See footnote following ref, 3.

29 W. E. McEwen, W. E. Conrad and C. A. Vander Werf, J. Amer. Chem. Soc. 74, 1168 (1952).

${ }^{20}$ K. F. Schmidt, D. R. P. 427,858, April 20 (1926). 
support to the assumption that nitriles arise by elimination. The syn-H oximes have been shown to be formed first ${ }^{8,31}$ when benzaldehydes are oximated, even under conditions of acidity where the ant $\mathrm{i}-\mathrm{H}$ salts are more stable. However, aldoxime derivatives are indeed converted to nitriles readily by treatment with bases (conditions that do not promote the Beckmann rearrangement in general). ${ }^{32}$ It would appear that nitrile formation from aldoxime derivatives is a base-catalyzed elimination, which may occur from both the syn-H and anti-H forms, but more readily with the latter, which allows trans elimination. If these characteristics also hold for the Schmidt reaction on aldehydes, it is not necessary to postulate that the less stable iminodiazonium ion configuration is formed fastest, and the observed facts can be accounted for in terms of an extension of the elimination concept. Elimination from $\mathrm{Ar}-\mathrm{CH}=\mathrm{N}-\mathrm{N}_{2}{ }^{+}$ (Schmidt reaction intermediate) would be expected to be a far easier process than from $\mathrm{Ar}-\mathrm{CH}=\mathrm{NOAc}$ (oxime derivative), since the positive charge would promote the acidity of the hydrogen, and molecular nitrogen is a much better leaving group than carboxylate anion; it might even under some conditions become an $E_{1}$ process.

In the sulfuric acid-catalyzed Schmidt reaction, the principal base available to remove the aldehyde hydrogen and so form a nitrile is bisulfate ion. At low ratios of sulfuric acid to benzaldehyde and in the presence of sodium bisulfate, elimination could occur more readily than at the higher ratios, at which the formation of formanilides was found to be promoted. With elimination suppressed by the higher acidity, the usual Schmidt rearrangement becomes more important, and since the syn-H configuration, being the more stable, is predominantly present, aryl migration ensues to produce formanilide.

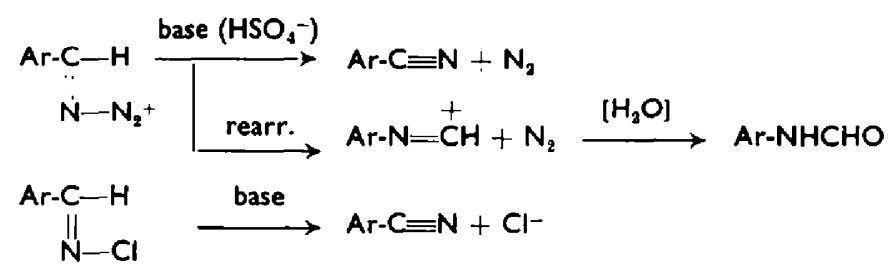

Two of the substituents, nitro and methoxy, had marked effects on the ratio of nitrile to formanilide formed, each promoting nitrile formation. The effect of the nitro group is easily attributed to an increase in the acidity of the eliminated hydrogen, and is in agreement with published observations of the effect of substituents on other eliminations, of which the kinetic study of the base-catalyzed elimination (presumably cis) from $\mathrm{N}$-chlorobenzaldimines (presumably syn-H) is perhaps the most pertinent, ${ }^{33}$ and also to the retarding effect of the nitro group on aryl migration.

The reported effect of the methoxy group is anomalous, since this group usually retards eliminations. An explanation for depressed aryl migration, but not the complete absence of it, can be developed from a consideration of the effect of the methoxy group in $p$-methoxybenzophenone; as has been discussed in an earlier section, enhanced migration of the anisyl group is observed, and may result in part from the ability of the $p$-methoxy group to promote acid-catalyzed interconversion

si H. Lindemann and K.-T. Tschang, Ber. Dtsch. Chem. Ges, 60, 1725 (1927).

$\$$ J. Meisenheimer and W. Theilacker, Stereochemie (Edited by K. Freudenberg), p. 974 et seq. Franz Deuticke, Leipzig (1932).

st C. R. Hauser, J. W. Le Maistre and A. E. Rainsford, J. Amer. Chem. Soc. 57, 1056 (1935). 
between syn and anti forms. Since the anti-H form of the iminodiazonium ion would be expected to undergo trans-elimination very much faster than cis-elimination from the syn-H form, a path would thereby be opened for nitrile formation to prevail markedly over formanisidide formation by aryl migration. Elimination via the less stable anti-H form would add only a small amount to the energy barrier, inasmuch as the energy difference between the syn and anti forms of aldoximes has been found to be of the order of 1 to $2 \mathrm{kcal}^{34}$ Furthermore, increasing acidity of the medium, which for most benzaldehydes retards elimination, would in this case have in addition a counteracting effect, in the form of accelerating the interconversion to the much more rapidly eliminating anti-H form. In this way also, the intrinsically greater ability of the anisyl group to migrate would be overridden. The foregoing interpretation receives additional support from the fact that neither syn-nor anti-anisaldoxime undergo Beckmann rearrangement to give formanisidide, both isomers giving solely anisonitrile or anisamide. 186,21

Since the low material balance reported for the Schmidt reaction on anisaldehyde at the higher ratio of sulfuric acid raises the question of whether a considerable amount of formanisidide may not after all have been formed, and either lost by sulfonation or condensation with anisaldehyde, or diverted to tetrazole, we re-examined this experiment. We are able to confirm the qualitative result of McEwen, et al. that anisonitrile or its hydrolysis products are the major products, and to state that the formation of tetrazoles is real, although small. We isolated less than 1 per cent of anisidine (presumably derived from formanisidide), while the sum of anisonitrile and products from it amounted to ca. 72 per cent. Among these was 4.7 per cent of a basic solid, apparently identical with the $\mathrm{N}$-anisoylanisamidine reported by Francis and Davis. ${ }^{35}$ Examination of the aqueous mother liquor for non-extractable organic substances showed the presence of much diazotizable amine, presumably in the form of a sulfonic acid. Sequestering of formanisidide by sulfonation is not surprising in view of the fact that its ring is the most reactive of all those in the systems studied in the Schmidt reaction. Furthermore, experiments with formanisidide and anisaldehyde in simulated Schmidt reaction conditions showed that formanisidide does not survive, but undergoes conversion to anisaldehyde $p$-methoxyanil and then to sulfonation and hydrolysis products. We were also able to isolate 1.4 per cent of 1-p-anisyl-5-aminotetrazole (which could as well have arisen by a secondary reaction on anisonitrile as from initial migration of the anisyl group). While we were not able to assess quantitatively the production of substances derived from aryl migration, we can say that the Schmidt reaction on anisaldehyde should no longer be regarded as anomalous.

In summary, we can say that the mechanism for the Schmidt reaction on ketones proposed in 1948 can, when considered with insight, account for the many apparently anomalous phenomena that have been encountered since then, and that geometrical isomerism lies at the root of the causes of the observed ratios of amide isomers. The simplified interpretation in the form of the rule that that group migrates preferentially which has the greatest bulk in the neighborhood of the carbonyl group may have drastic exceptions where either conjugation or chelation come into play, and may owe its reliability in saturated aliphatic systems to the fact that migration aptitudes have their influence in the same direction.

34 W. Swietoslawski and M. Popow, Bull. Soc. Chim. Fr. [4], 35, 137 (1924).

36 F. E. Francis and O. C. M. Davis, J. Chem. Soc. 85, 1535 (1904). 


\section{EXPERIMENTAL*}

Preparation of ketones. o-Methylbenzophenone, b.p. $128-130^{\circ} / 1.5 \mathrm{~mm}$ (reported ${ }^{36} 134-137^{\circ} / 2 \mathrm{~mm}$ ) was prepared from $o$-tolunitrile and phenylmagnesium bromide. o-Ethylbenzophenone, b.p. $108-111^{\circ} / 0 \cdot 3 \mathrm{~mm}$ (reported ${ }^{37} 165^{\circ} / 18 \mathrm{~mm}$ ) was prepared from o-ethylbenzonitrile, b.p. $79 \cdot 5^{\circ} / 4 \cdot 5 \mathrm{~mm}$. $n_{\mathrm{D}}^{20} 1.5229, d_{\mathrm{S}}^{2 \mathrm{~s}} 0.9715$ (reported ${ }^{28}$ b.p. $103^{\circ} / 19 \mathrm{~mm}, n_{\mathrm{D}}^{20} 1.5232$ ), and phenylmagnesium bromide, o-Ethylbenzophenone 2,4-dinitrophenylhydrazone, prepared in the conventional manner, melted over a wide range even when freed from reactants. $t$ Incomplete dissolution of this product in boiling alcohol left an undissolved portion which, after recrystallization from alcohol and ethyl acetate, gave orange needles, m.p. 174-178.5 . (Found: C, 64.44; H, 4.69; N, 14.02. $\mathrm{C}_{21} \mathrm{H}_{18} \mathrm{~N}, \mathrm{O}_{4}$ requires: C, $64.60 ; \mathrm{H}, 4.65 ; \mathrm{N}, 14.35 \%$ ).

1-Benzoylnaphthalene, m.p. $75-76^{\circ}$ (reported ${ }^{39} 75 \cdot 5-76^{\circ}$ ) was prepared from $\alpha$-naphthylmagnesium bromide and benzonitrile and recrystallized from alcohol.

o-Isopropylbenzonitrile and o-isopropylbenzamide. The mixture of products from the mononitration ${ }^{40}$ of cumene at $25^{\circ}$ was fractionated twice through a three-foot spinning-band column under reduced pressure, and a center cut of $o$-nitrocumene of constant boiling point, $112^{\circ} / 13 \mathrm{~mm}$, and refractive index, $n_{\mathrm{D}}^{20} 1 \cdot 5248$, was obtained (reported b.p. $115^{\circ} / 13 \mathrm{~mm}, 41 n_{\mathrm{D}}^{20} 1 \cdot 5248,41 \quad 1.52420,40$ $\left.1.5259^{42}\right)$. $o$-Nitrocumene was reduced in $90 \%$ yield with powdered iron and hydrochloric acid according to the method of Haun and Kobe ${ }^{*}$ for mixed nitrocumenes, but using longer reaction time. The amine hydrochloride was recrystallized from benzene before further use and was converted in part to the free amine, b.p. 102.5-103.5\%12.5 mm, $n_{\mathrm{D}}^{2 \mathrm{~s}} 1.5472, d_{4}^{25} 0.9614$ (reported ${ }^{4 s}$ b.p. $\left.102^{\mathrm{c}} / 14 \mathrm{~mm}, n_{\mathrm{D}}^{2 \mathrm{~s}} 1.5494\right)$.

A diazotized solution of $25.7 \mathrm{~g} o$-isopropylaniline hydrochloride was neutralized and combined with a solution of cuprous cyanide." The addition was made as rapidly as possible in order to avoid excessive decomposition of the diazonium salt, and the mixture was kept at $-3-0^{\circ}$ all the time. The stirred mixture was allowed to warm to room temp and finally heated on the steam bath until evolution of nitrogen ceased. It was distilled with super-heated steam and ca. $2 \mathrm{l}$. of distillate was collected. Distillation of the benzene extracts of the steam distillate afforded $12.8 \mathrm{~g} \mathrm{(59 \% )} o$-isopropylbenzonitrile, b.p. 101-104\% $/ 15 \mathrm{~mm}$. A small portion was redistilled for analysis, b.p. $106^{\circ} / 16 \mathrm{~mm}$, $n_{\mathrm{D}}^{\text {ses }}$ 1.5144 (Found: C, 82.79; H, 7.55; N, 9.52. $\mathrm{C}_{10} \mathrm{H}_{11} \mathrm{~N}$ requires: $\mathrm{C}, 82.72 ; \mathrm{H}, 7.64: \mathrm{N}, 9.65 \%$.

o-Isopropylbenzonitrile $(8.2 \mathrm{~g})$ was converted by $30 \%$ hydrogen peroxide and alcoholic base to o-isopropylbenzamide $\left(4 \mathrm{~g}, 67 \%\right.$ based on recovered nitrile), white needles, m.p. 123-123. $5^{\circ}$, from petroleum ether (b.p. $90-100^{\circ}$ ) (Found: $\mathrm{C}, 73.73 ; \mathrm{H}, 8.02 ; \mathrm{N}, 8.59 . \mathrm{C}_{10} \mathrm{H}_{13} \mathrm{NO}$ requires: $\mathrm{C}, 73.59$; $\mathrm{H}, 8.03 ; \mathrm{N}, 8.58 \%$.

o-Isopropylbenzophenone. To a solution of the Grignard reagent from $12.1 \mathrm{~g}$ bromobenzene in $80 \mathrm{ml}$ ether, prepared under nitrogen, a solution of $9 \cdot 2 \mathrm{~g}$ o-isopropylbenzonitrile in $10 \mathrm{ml}$ ether was added dropwise (3-4 min) at room temp. The mixture was heated under reflux for $1.5 \mathrm{hr}$ and allowed to stand over-night at room temp. It was poured on ice, acidified with $50 \% \mathrm{H}_{2} \mathrm{SO}_{4}$ and heated on the steam bath for $24 \mathrm{hr}$ after the ether was removed. The organic layer was taken up in benzene and washed with dil sodium carbonate. Distillation at $0.6 \mathrm{~mm}$ gave $10.9 \mathrm{~g}(77 \%)$ of $o$-isopropylbenzophenone, collected in two fractions: (a) b.p. $121-123^{\circ}(1 \cdot 7 \mathrm{~g})$ and (b) b.p. $123 \cdot 5 \cdot 124^{\circ}$ $(9.2 \mathrm{~g})$. A sample from the latter was used for analysis (Found: $\mathrm{C}, 85.47 ; \mathrm{H}, 6.95 . \mathrm{C}_{16} \mathrm{H}_{18} \mathrm{O}$ requires: C, $85.68 ; \mathrm{H}, 7 \cdot 19 \%$ ).

- Melting points are uncorrected and analyses are by Spang Microanalytical Laboratory and by Mrs. A. Griffin and Mr. G. Kodama of the Department of Chemistry, University of Michigan.

$\dagger$ It is quite reasonable to expect two stereoisomeric 2, 4-dinitrophenylhydrazones from 0 -substituted benzophenones; cf. similar derivatization of $m$-chlorophenyl $\alpha$-naphthyl ketone by R. S. Cahn, W. O. Jone and J. L. Simonsen, J. Chem. Soc. 444 (1933). Separation of their mixtures may, however, be considerably difficult. We have not been able to improve the melting range $184-190^{\circ}$, reported by $M$. S. Newman and C. D. McCleary, J. Amer. Chem. Soc. 63, 1517 (1941), for $O$-methylbenzophenone 2,4-dinitrophenylhydrazone. Likewise, from o-ethylbenzophenone only one isomer was obtained relatively pure.

34 I. I. Lapkin and A. V. Lyubimova, Zhur. Obshchei Khim. 19, 707 (1949); Chem. Abstr. 44, 1058' (1950).

s7 E. Bergmann, J. Org. Chem. 4, 1 (1939).

88 H. R. Snyder and G. I. Poos, J. Amer. Chem. Soc. 71, 1057 (1949).

30 M. W. D. Cohen, Rec. Trav. Chim. 38, 120 (1919).

to J. W. Haun and K. A. Kobe, Industr. Engng. Chem. 43, 2355 (1951).

${ }^{41}$ H. C. Brown and W. H. Bonner, J. Amer. Chem. Soc. 74, 605 (1954).

42 W. G. Brown and H. Reagan, J. Amer. Chem. Soc. 69, 1032 (1947).

48 C. Hansch and G. Helmkamp, J. Amer. Chem. Soc. 73, 3080 (1951).
"H. T. Clarke and R. R. Read, Organic Syntheses (2nd Ed.) Coll. Vol. I, p. 514. John Wiley, New York (1941). 
o-Isopropylbenzophenone 2,4-dinitrophenylhydrazones were prepared from fraction (a) of o-isopropylbenzophenone. Approximately half of the crude product was dissolved in a limited amount of boiling alcohol containing a little ethyl acetate. The undissolved portion was then recrystallized twice from alcohol and ethyl acetate, giving scarlet needles, m.p. 204-206. $8^{\circ}$ (Found: C, 65.32; $\mathrm{H}, 4.80 ; \mathrm{N}, 13.67$. $\mathrm{C}_{21} \mathrm{H}_{20} \mathrm{~N}_{4} \mathrm{O}$, requires: $\mathrm{C}, 65.33 ; \mathrm{H}, 4.99 ; \mathrm{N}, 13.86 \%$ ).

The portion of the product which dissolved in alcohol was recovered and again treated with an insufficient amount of boiling solvent. This time, however, the soluble portion of the partially dissolved material was retained. Repetition of this process finally afforded a minute amount of orange needles, m.p. $142-143^{\circ}$ (Found: $\mathrm{C}, 65 \cdot 46 ; \mathrm{H}, 4 \cdot 78 ; \mathrm{N}, 14 \cdot 18 . \mathrm{C}_{22} \mathrm{H}_{30} \mathrm{~N}, \mathrm{O}$, requires: $\mathrm{C}$, $65.33 ; \mathrm{H}, 4.99 ; \mathrm{N}, 13.86 \%$ ).

It is not certain whether this lower melting 2,4-dinitrophenylhydrazone is a structural or geometrical isomer of the main product.

o-Bromo-t.-butylbenzene. Twelve grams of 2-bromo-4-nitro-t.-butylbenzenets was reduced in a Parr hydrogenator in the presence of $0.1 \mathrm{~g}$ Adams catalyst $80 \mathrm{ml}$ alcohol and $10 \mathrm{ml}$ conc $\mathrm{HCl}$. The yield of 2-bromo-4-amino-t.-butylbenzene hydrochloride ${ }^{46}$ was quantitative; it was deaminated to o-bromo-t.-butylbenzene, $n_{\mathrm{D}}^{30} 1 \cdot 5438$, as described by Crawford and Stewart. ${ }^{66}$

In another instance, when a neutral alcoholic medium and a higher ratio of nitro-compound to catalyst were employed $(19.5 \mathrm{~g}-0.1 \mathrm{~g})$, products resulting from incomplete reduction were also isolated. They precipitated from the reaction mixture as an orange solid $(1 \mathrm{~g})$, which was separated by chromatography on alumina with pet ether (b.p. $30-60^{\circ}$ ) as solvent into two compounds:

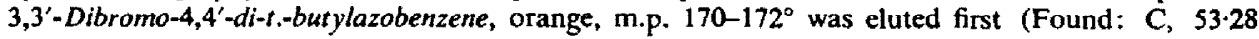
$\mathrm{H}, 5 \cdot 36 . \mathrm{C}_{20} \mathrm{H}_{24} \mathrm{Br}_{2} \mathrm{~N}_{3}$ requires: $\mathrm{C}, 53 \cdot 13 ; \mathrm{H}, 5 \cdot 35 \%$ ).

3,3-dibromo-4.4'-di-t.-butylazoxybenzene, yellow, m.p. 135-136 , was eluted last. (Found: C, $51.50 ; \mathrm{H}, 5 \cdot 10 ; \mathrm{N}, 5.98, \mathrm{C}_{20} \mathrm{H}_{24} \mathrm{Br}_{2} \mathrm{~N}_{2} \mathrm{O}$ requires: $\mathrm{C}, 51.53 ; \mathrm{H}, 5.17 ; \mathrm{N}, 5.98 \%$ ).

$\mathrm{o}-t .-$ Butylbenzophenone, o-t.-butylbenzophenone imine and hydrochloride. To a solution of the Grignard reagent from $8 \mathrm{~g} o$-bromo-t.-butylbenzene in $40 \mathrm{ml}$ ether was added at room temp $10.6 \mathrm{~g}$ freshly distilled benzoyl chloride in $10 \mathrm{ml}$ ether, causing vigorous ebullition and instantaneous precipitation of salts. The mixture was refluxed for $6 \mathrm{hr}$, then poured in iced water. The organic layer was shaken several times with $25 \% \mathrm{NaOH}$ until removal of benzoyl chloride by hydrolysis was complete. Distillation gave a forerun of t.-butylbenzene $(27 \%)$ and $5.9 \mathrm{~g}(66 \%)$-t.-butylbenzophenone, b.p. $124.5-125^{\circ} / 0.4 \mathrm{~mm}$, which gradually solidified and, after recrystallization from aqueous methanol, melted at $71-72^{\circ}$. (Found: $C, 85.84 ; \mathrm{H}, 7.66 . \mathrm{C}_{17} \mathrm{H}_{18} \mathrm{O}$ requires: $\mathrm{C}, 85.67$; $\mathrm{H}, 7 \cdot 61 \%$.

The addition of $4.2 \mathrm{~g}$ benzonitrile to the Grignard reagent from $8.7 \mathrm{~g} 0$-bromo-t.-butylbenzene gave $o$-t.-butylbenzophenone imine, which was isolated as the hydrochloride $(4 \cdot 6 \mathrm{~g}, 42 \%)$, m.p. $248-250^{\circ}$ after recrystallization from alcohol. (Found: C, 74.56; H, 7.45; N. 5.36. $\mathrm{C}_{17} \mathrm{H}_{20} \mathrm{ClN}$ requires: $\mathrm{C}, 74.57 ; \mathrm{H}, 7 \cdot 36 ; \mathrm{N}, 5 \cdot 12 \%$ ). The free imine, after repeated recrystallizations from light pet ether, m.p. $58-59 \cdot 5^{\circ}$. (Found: $\mathrm{N}, 5 \cdot 84 . \mathrm{C}_{17} \mathrm{H}_{19} \mathrm{~N}$ requires: $\mathrm{N}, 5 \cdot 90 \%$ ).

The imine was not appreciably hydrolyzed to the ketone by refluxing in conc hydrochloric acid overnight. Likewise it was recovered unchanged in $95 \%$ yield after boiling in aqueous alcoholic potassium hydroxide for 8 days.

o-t $t$-Butylaniline. $o$-Nitro-t.-butylbenzene $(13.5 \mathrm{~g})$, prepared in $76 \%$ yield by the deamination $46, *$ of 2-nitro-4-amino-t.-butylbenzene, ${ }^{47}$ was reduced with hydrogen and Adams catalyst to o-t.-butylaniline $\left(8.5 \mathrm{~g}, 76 \%\right.$ ), b.p. $112.5 \% \mathrm{~mm}, d^{25} 0.9576, n_{\mathrm{D}}^{20} 1.5455$ (reported ${ }^{48}$ b.p. $106.5 \% 10 \mathrm{~mm}$ $n_{\mathrm{D}}^{30} 1.5453$ ), after isolation via the hydrochloride and distillation through a one-foot spinning band column at $13 \mathrm{~mm}$.

Preparation of amides. The amides used in the preparation of calibration mixtures for the infrared

* Both procedures given in ref. 45 were used. Procedure I, which employs hypophosphorous acid as the source of the requisite acidity in the diazotization step, gave lower yields plus $17 \%$ of buff colored 1,3-bis-(3-nitro-4-t.-butylphenyl) triazene, m.p. 187-189. (Found: C, 60.13; H, 6.15. $\mathrm{C}_{90} \mathrm{H}_{25} \mathrm{~N}_{3} \mathrm{O}_{4}$ requires: $\mathrm{C}, 60 \cdot 13 ; \mathrm{H}, 6 \cdot 31 \%$ ).

The triazene was not isolated when hydrochloric acid (Procedure II), a stronger acidic medium, was used during diazotization.

4s M. Crawford and F. H. C. Stewart, J. Chem. Soc. 4443 (1952).

48 N. Komblum and D. C. Iffland, J. Amer. Chem. Soc. 71, 2137 (1949).

17 J. B. Shoesmith and A. Mackie, J. Chem. Soc. 2336 (1928).

${ }^{48}$ H. C. Brown and K. L. Nelson, J. Amer. Chem. Soc. 75, 27 (1953). 
analysis were synthesized by standard methods from the corresponding acid chlorides and amines, unless otherwise indicated: o-toluanilide, m.p. $125-126^{\circ}$ (reported ${ }^{10} 129-129.5^{\circ}$ ); benzo-o-toluidide, m.p. $142 \cdot 5-143^{\circ}$ (reported ${ }^{\circ} 142-143^{\circ}$ ); o-ethylbenzanilide, m.p. 141-142.5 ; benzo-o-ethylanilide, m.p. $152.5-153^{\circ}$ (reported $^{\mathrm{s} 0}$ m.p. $146^{\circ}$ ). (Found: C, 79.88; H, 6.77; N, 6.16. Calc. for $\mathrm{C}_{15} \mathrm{H}_{1 \mathrm{~s}} \mathrm{NO}$ : C, 79.97; H, 6.71; N, 6.22\%); benzo-o-isopropylanilide, m.p. 147-147.5 (reported ${ }^{51}$ m.p. $149^{\circ}$ ); benzo-o-t.-butylanilide, m.p. $194-194.8^{\circ}$ (reported ${ }^{51}$ m.p. $196^{\circ}$ ) (also exists in another modification,

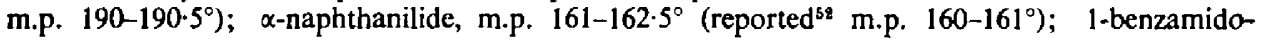
naphthalene, m.p. $159-161^{\circ}$ (reported ${ }^{53}$ m.p. $159-160^{\circ}$ ).

o-Isopropylbenzanilide, prepared from 0 -isopropylbenzoic acid obtained by the method of Sudborough, 54 had m.p. 135.5-136.5. (Found: $C, 80 \cdot 16 ; \mathrm{H}, 7 \cdot 07 ; \mathrm{N}, 5 \cdot 88 . \mathrm{C}_{16} \mathrm{H}_{17} \mathrm{NO}$ requires: C, $80 \cdot 30 ; \mathrm{H}, 7 \cdot 16 ; \mathrm{N}, 5 \cdot 85 \%$ ).

o-t.-Butylbenzanilide, m.p. $178 \cdot 5-180 \cdot 5^{\circ}$, was prepared from $o$-t.-butylphenylmagnesium bromide and phenyl isocyanate. (Found: $\mathrm{C}, 80.35 ; \mathrm{H}, 7 \cdot 47 ; \mathrm{N}, 5 \cdot 50 . \mathrm{C}_{17} \mathrm{H}_{18} \mathrm{NO}$ requires: $\mathrm{C}, 80.57 ; \mathrm{H}, 7 \cdot 56$; $\mathrm{N}, 5 \cdot 53 \%$ ).

Schmidt reactions. The procedure used, unless otherwise stated, was to add $1.0 \mathrm{~g}$ solid sodium. azide portionwise to a solution of 0.01 mole ketone and 0.028 mole conc sulphuric acid in $25 \mathrm{~g}$ fused trichloroacetic acid at $60=2^{\circ}$. The addition was customarily made over $3-9 \mathrm{hr}$, and the reaction was allowed to continue for several hours until visible gas evolution had ceased. The products precipitated when the mixture was diluted with water and neutralized with ammonia or dil alkali. The mixture of amides was collected by filtration, washed with water, and freed of unreacted ketone either by steam distillation or by washing with a few $\mathrm{ml}$ cold light pet ether. When the nitrogen analysis of the mixture was in good agreement with the calculated value for the amides the mixture was used in the spectrophotometric determination of isomer ratios without further purification.

With an addition time of $2.75 \mathrm{hr}, 1.96 \mathrm{~g}$ o-methylbenzophenone gave $1.70 \mathrm{~g}$ amides (Found: $\mathrm{N}, 6.62$. Calc. for $\mathrm{C}_{1 \mathrm{a}} \mathrm{H}_{1 \mathrm{~s}} \mathrm{ON}: \mathrm{N}, 6.63 \%$ ), and $0.26 \mathrm{~g}$ of yellow oil (pet ether wash) presumed to be unreacted ketone. With an addition time of $9 \mathrm{hr}$, the yield of amides was $2 \cdot 11 \mathrm{~g}$ (Found: $\mathrm{N}, 6.65 \%$ ). o-Ethylbenzophenone $(2 \cdot 10 \mathrm{~g}$ ) with an addition time of $4.5 \mathrm{hr}$ gave $1.81 \mathrm{~g}$ amides (Found: $\mathrm{N}, 6.28$. Calc. for $\mathrm{C}_{18} \mathrm{H}_{15} \mathrm{ON}$ : $\mathrm{N}, 6.22 \%$ ) and $0.33 \mathrm{~g}$ unreacted ketone (pet ether wash). With an addition time of $6 \mathrm{hr}$ the yield of amides was $2 \cdot 15 \mathrm{~g}$, after purification by steam distillation (Found: $\mathrm{N}, 6.25 \%$ ). The distillation removed only $0.03 \mathrm{~g}$ of a mixture of amides and ketone, which was not considered further.

From $2.24 \mathrm{~g} o$-isopropylbenzophenone with $9.5 \mathrm{hr}$ addition time $2.30 \mathrm{~g}$ amides was obtained, after purification by steam distillation (Found: N, 5.88. Calc. for $\mathrm{C}_{18} \mathrm{H}_{17} \mathrm{ON}: \mathrm{N}, 5 \cdot 85 \%$ ). With an addition time of $7 \mathrm{hr}$ and the same method of purification, another sample of 0 -isopropylbenzophenone gave $2.23 \mathrm{~g}$ amides (Found: $\mathrm{N}, 6.05 \%$ ), and $0.07 \mathrm{~g}$ of a mixture of amides and ketone.

The Schmidt reaction of $o$-t.-butylbenzophenone was performed as follows. Sodium azide $\left(3.4 \mathrm{~g}\right.$ ) was added in small portions during $76 \mathrm{hr}$ to a solution of $3.4 \mathrm{~g}$ of the ketone (m.p. $70.5-72^{\circ}$; chromatographed in pet ether over alumina) and $12 \mathrm{~g}$ conc sulphuric acid in $100 \mathrm{~g}$ trichloroacetic acid. After standing for $12 \mathrm{hr}$ the mixture was poured in iced water and basified. The precipitated solid was filtered, washed free of base and dried. It was combined with the evaporated ether extracts of the aqueous phase, dissolved in ca. $50 \mathrm{ml}$ benzene and chromatographed over alumina $(300 \mathrm{~g})$. Unreacted ketone $\left(9.17 \mathrm{~g}, \mathrm{~m} . \mathrm{p} .68-70.5^{\circ}\right)$ was eluted first with benzene. After a clean break, during which the solvent was gradually changed to chloroform and then to absolute alcohol, an "amide fraction" was eluted with the latter, weighing $0.237 \mathrm{~g}$ and consisting of brown semi-solid material. By recrystallization from a mixture of benzene and pet ether, $0.063 \mathrm{~g}$ of almost white solid was obtained. The unreclaimed material $(0.173 \mathrm{~g})$ was chromatographed again in the same manner. The first fraction $(0.01 \mathrm{~g})$ contained oily material soluble in pet ether and was discarded. It was followed by fractions containing a white solid and, later, oil which could be induced to crystallize by treating with benzene and pet ether and seeding. The combined yield of all crystalline material from the "amide fraction" was thus raised to $0.118 \mathrm{~g}$ (Found: $\mathrm{N}, 6.01,6.03$. Calc. for $\mathrm{C}_{12} \mathrm{H}_{18} \mathrm{NO}$ : $\mathrm{N}, 5.53 \%$ ). It is possible that it was contaminated with some sym-phenyl-o-t-butylphenylurea

49 A. Brückner, Liebig's Ann. 205, 130 (1880).

$80 \mathrm{~J}$. von Braun, O. Bayer and G. Blessing, Ber. Disch. Chem. Ges. 57, 392 (1924).

11 P. Grammaticakis, Bull. Soc. Chim. 134 (1949).

$\$ 2$ M. Betti and A. Beccioloni, Gazz. Chim. Ital, 45(II), 224 (1915).

b. Loevenich and A. Loeser, Ber. Dtsch. Chem. Ges. 60, 322 (1927).

s4 J. J. Sudborough, J. Chem. Soc. 67, 602 (1895). 
(Calc. for $\mathrm{C}_{17} \mathrm{H}_{20} \mathrm{~N}_{2}: \mathrm{N}, 10.5 \%$ ). The infrared spectrum of the product disclosed ca. $20 \%$ of contamination. The isomer ratio obtained thereby should be considered only as a very rough estimate.

1-Benzoylnaphthalene $(2.32 \mathrm{~g})$ with an addition time of $8 \mathrm{hr}$ gave $2.42 \mathrm{~g}$ amides (washed with pet ether b.p. $90-100^{\circ}$ ) (Found: $\mathrm{N}, 5 \cdot 67$. Calc. for $\mathrm{C}_{17} \mathrm{H}_{18} \mathrm{NO}: \mathrm{N}, 5.66 \%$ ).

Oximations and Beckman rearrangements. The oximations at $118^{\circ}$ were performed by maintaining at a gentle reflux a solution of 0.01 mole ketone and $1.0 \mathrm{~g}$ hydroxylamine hydrochloride in $10 \mathrm{ml}$ pyridine (the temperature of the refluxing liquid was $118 \pm 2^{\circ}$ ). After pouring in water, crystallization of the oily oximes was facilitated by acidifying with dil hydrochloric acid and was usually complete in two to $3 \mathrm{hr}$. The solid oximes were filtered, washed with water and dried. They were rearranged at room temp in benzene solution by the addition of $3 \mathrm{~g}$ phosphorus pentachloride in 3 portions during $\frac{1}{2} \mathrm{hr}$. After 3-8 hr, the mixture was decomposed with water, the benzene was evaporated and the crystalline amides were filtered and washed with water. Occasionally they were washed with IN NaOH to remove unreacted oximes, but a significant amount was never found. After drying, the amides were washed with light pet ether to remove unreacted ketonc.

Oximation of $1.96 \mathrm{~g} o$-methylbenzophenone gave $2.03 \mathrm{~g}(96 \%)$ of oxime which afforded upon rearrangement $1.99 \mathrm{~g}$ amides (Found: $\mathrm{N}, 6 \cdot 62$. Calc. for $\mathrm{C}_{14} \mathrm{H}_{13} \mathrm{ON}: \mathrm{N}, 6.63 \%$ ).

From $2 \cdot 10 \mathrm{~g} o$-ethylbenzophenone $2 \cdot 18 \mathrm{~g}(97 \%)$ of oximes was obtained, giving $2 \cdot 11 \mathrm{~g}$ amides upon rearrangement (Found: $\mathrm{N}, 6 \cdot 18$. Calc. for $\mathrm{C}_{15} \mathrm{H}_{15} \mathrm{ON}: \mathrm{N}, 6 \cdot 22 \%$ ).

Oximation of $2.24 \mathrm{~g} \mathrm{o}$-isopropylbenzophenone gave $2.32 \mathrm{~g}(97 \%)$ oximes, which was converted to $2 \cdot 29 \mathrm{~g}$ amides (Found: $\mathrm{N}, 5 \cdot 89$. Calc. for $\mathrm{C}_{10} \mathrm{H}_{17} \mathrm{ON}: \mathrm{N}, 5 \cdot 85 \%$ ).

The oximes from 1-benzoylnaphthalene $(2.32 \mathrm{~g})$ did not completely crystallize after standing for $8 \mathrm{hr}$ in the refrigerator, but did so when kept an additional $3 \mathrm{hr}$ at room temp. The yield of amides was $2.05 \mathrm{~g}$ (Found: $\mathrm{N}, 5.41$. Calc. for $\mathrm{C}_{17} \mathrm{H}_{13} \mathrm{ON}$ : N, $5.66 \%$ ).

The oximations at $60^{\circ}$ were performed in a similar manner, using an oil bath at $60 \doteq 2$, and were allowed to proceed for 12 days. In anticipation that the presence of unreacted ketone might render difficult the crystallization of the oximes, the reaction mixtures were decomposed with water and then extracted with benzene. The extracts were washed with $10 \% \mathrm{HCl}$, then with a solution of sodium chloride until frec of acid, and dried over magnesium sulphate. The Beckman rearrangement was performed without isolation of the oximes. The resulting amides were treated as above.

In this manner $1.97 \mathrm{~g} o$-methylbenzophenone gave $1.97 \mathrm{~g}$ amides (Found: $\mathrm{N}, 6.54 \%$ ). $\quad o$-Ethylbenzophenone $(2.10 \mathrm{~g})$ gave $2.08 \mathrm{~g}$ amides (Found: $\mathrm{N}, 6.24 \%$ ). $o$-Isopropylbenzophenone $(2.05 \mathrm{~g})$ gave $1.64 \mathrm{~g}$ amides (Found: $\mathrm{N}, 5.82 \%$ ) and $0.42 \mathrm{~g}$ ketone, left as an amber oil upon evaporation of the pet ether wash.

Determination of isomer ratios. The ratios of isomeric amides were determined by infrared analysis, using $5 \%(w / v)$ solutions in chloroform, matched $0.1 \mathrm{~mm}$ sodium chloride cells and a Perkin-Elmer Model 21 Infrared Spectrophotometer. Calibration mixtures were prepared from pure samples of the amides and measurements werc made at several selected frequencies. A priori weights were assigned to the measurements at each frequency based on the rate of change of the transmittance with composition and the reproducibility of the transmittance readings. The value of the ratio was taken as the average of the values obtained at various frequencies. In general the weighted averages differed less than one percent unit from the unweighted. The following frequencies were used for the products of each ketone: $o$-Methylbenzophenone: $1602,1473,1478,1443,1317$ and $702 \mathrm{~cm}^{-1} .0$-Ethylbenzophenone: $1595,1463,1452$ and $1315 \mathrm{~cm}^{-1}$. o-Isopropylbenzophenone: 1594, 1580,1466-8,1450, 1314 and $700 \mathrm{~cm}^{-1}$. o-t-Butylbenzophenone: 1602,1580, 1475 and $1315 \mathrm{~cm}^{-1}$. 1-Benzoylnaphthalene: $1596,1485,1460,1438,1344,1313$ and $700 \mathrm{~cm}^{-1}$. The italicized frequency was the most sensitive.

Schmidt reaction on anisaldehyde. To $23.4 \mathrm{~g}$ sodium azide overlaid with $225 \mathrm{ml}$ "reagent" grade benzene was added $55 \mathrm{ml}$ conc. $\mathrm{H}_{2} \mathrm{SO}_{4}$ dropwise, while the temp was kept between 10 and $15^{\circ}$. The sulphuric acid was then followed by $20.4 \mathrm{~g}$ anisaldehyde (Eastman "White Label"), also added dropwise at $10-15^{\circ}$, and the mixture was stirred at room temp for $2 \mathrm{hr}$ more, heated at ca. $45^{\circ}$ for $1 \mathrm{hr}$, and then decomposed with ice. The resulting yellow-brown precipitate was filtered off and washed with benzene and water; wt. $17.02 \mathrm{~g}$. This material was then swirled with $250 \mathrm{ml} 2 \% \mathrm{NaOH}$ solution at room temp; the dull yellow residue of crude anisamide weighed $14 \mathrm{~g}, \mathrm{~m} . \mathrm{p} .157-162^{\circ}$. Recrystallization from acetone gave successive crops of glassy crystals of anisamide, m.p. 167-168 ${ }^{\circ}$ (reported ${ }^{\mathrm{s}}$ m.p. $166 \cdot 5-167 \cdot 5^{\circ}$ ), total wt. $12 \cdot 3 \mathrm{~g}$.

${ }^{85}$ E. Bamberger and N. Pemsel, Ber. Dtsch. Chem. Ges. 36, 371 (1903). 
Concentration of the mother liquors and crystallization of the residue alternately from methanol and acetone gave $0.24 \mathrm{~g}$ of prisms, m.p. $231-233^{\circ}$ with effervescence, an approximately equal quantity of the same material of lower purity, and $0.31 \mathrm{~g}(1.5 \%)$ of $\mathrm{N}$-anisoylanisamidine, m.p. $156-158^{\circ}$, undepressed when mixed with a sample from another fraction of the reaction mixture (vide infra). (Owing to the closeness of their m.ps., anisamide, m.p. 166-1/2-167-1/2 ${ }^{\circ}$, and anisoylanisamidine, m.p. $162-163^{\circ}$, cannot be distinguished with certainty when not highly purified, and the identities reported in the following description were therefore in all cases confirmed by mixed m.ps.).

The substance of m.p. $231-233^{\circ}$ has the same empirical formula as anisamide, but its infrared spectrum (Nujol mull) differs from it as indicated: Anisamide: 3370, 3040-3160, 1685 shouldering on $1615,1575,1515$, and $1460 \mathrm{~cm}^{-1}$; isomer, m.p. 231-233': 3170-3250, 1605 (plus weak, broad shoulder in $1650-1720$ region), $1555,1485,1465 \mathrm{~cm}^{-1}$, plus additional differences at lower frequencies. (Found: $\mathrm{C}, 63.56 ; \mathrm{H}, 5.95 ; \mathrm{N}, 9 \cdot 34 . \mathrm{C}_{8} \mathrm{H}_{9} \mathrm{O}_{2} \mathrm{~N}$ requires: $\mathrm{C}, 63.56 ; \mathrm{H}, 6.00 ; \mathrm{N}, 9.27$ ). Hydrolysis of $0.11 \mathrm{~g}$ by heating for 4 days with $1: 1 \mathrm{HCl}$ gave $0.05 \mathrm{~g}$ anisic acid, m.p. 181-182 1/2 $2^{\circ}$ (reported se $^{\circ}$ m.p. $183-184^{\circ}$ ). The filtrate was made strongly basic with potassium hydroxide, heated for $4 \mathrm{hr}$, cooled, and treated with 4 drops benzoyl chloride. No benz-p-anisidide, or any other isoluble substance, was produced. Acidification of the mixture gave an immediate precipitate. The mixture was diluted to ca. $20 \mathrm{ml}$, heated to near boiling, and filtered. The solid so obtained was crude anisic acid, wt. $0.03 \mathrm{~g}, \mathrm{~m} . \mathrm{p} .174-179^{\circ}\left(180-182^{\circ}\right.$ when mixed with authentic anisic acid), total yield $72 \%$. Recrystallization of this crop from carbon tetrachloride gave $0.015 \mathrm{~g}, \mathrm{~m} . \mathrm{p} .180 \mathrm{1} / 2-183^{\circ}$. (When the hydrolysis was carried out with hydrochloric acid only, treatment of the filtrate from the first crop of anisic acid with benzoyl chloride and sodium carbonate gave an impure, solid, neutral substance, m.p. $159-164^{\circ}$, which may have been crude dianisamide, reported m.p. $170^{\circ 86}$ ). Although the analysis and hydrolysis of the substance of m.p. $231-233^{\circ}$ corresponds to a hydrate of anisoylamisamidine, we were unable to achieve an interconversion with it.

The liquid portion of the original reaction mixture (benzene-water solution) was separated into its layers, and the aqueous phase was extracted with ether. The combined non-aqueous phases were washed with sodium hydroxide solution and with water; acidification of these washings precipitated $0.22 \mathrm{~g}(1 \%)$ anisic acid, m.p. $180-183^{\circ}$. The washed benzene-ether solution was then allowed to stand with sat sodium bisulphite solution overnight to detect unreacted anisaldehyde, but only $0.2 \mathrm{~g}$ bisulphite addition compound was formed. Evaporation of the filtered organic phase left a tan, crystalline residue, wt. $2.5 \mathrm{~g}$. Extraction with warm ligroin-benzene mixture left $0.32 \mathrm{~g}$ anisamide $(1.4 \%)$ m.p. $168-170^{\circ}$. The extracts were evaporated and crystallized from methanol, giving a few glassy crystals, m.p. $209-215^{\circ}$. Dilution of the methanolic filtrate with water gave anisonitrile in several crops, total wt. $1 \cdot 34 \mathrm{~g}(7 \cdot 3 \%)$, m.p. from $55-59^{\circ}$ to $60-62^{\circ}$.

The aqueous sulphuric acid portion of the original reaction mixture was alkalized with a mixture of sodium and potassium hydroxides, which precipitated $0.86 \mathrm{~g}$ solid showing an indefinite m.p. Recrystallization from absolute alcohol (charcoal) gave $\mathrm{N}$-anisoylanisamidine in two crops, total wt. $0.67 \mathrm{~g}\left(3.2 \%\right.$ ), m.p. $161-163^{\circ}$ (Found: C, 67.63; H, 5.91; N, 9.74. Calc. for $\mathrm{C}_{16} \mathrm{H}_{16} \mathrm{O}_{3} \mathrm{~N}_{2}$ : $\mathrm{C}, 67.59 ; \mathrm{H}, 5.67 ; \mathrm{N}, 9 \cdot 85$ ). The infrared spectrum (Nujol mull) of a sample recrystallized from acetone showed absorptions at $3120-3200$ (with a prominent shoulder at $3200-3300$ ), 1605, 1565, and $1465 \mathrm{~cm}^{-1}$. Hydrolysis of $0.11 \mathrm{~g}$ by heating with $10 \% \mathrm{HCl}$ for several hours gave $0.115 \mathrm{~g}(98 \%)$

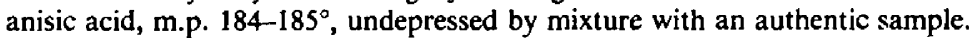

The alkaline, aqueous solution from which the crude anisoylanisamidine had been filtered was extracted repeatedly with chloroform and ether. Treatment of the aqueous layer with benzoyl chloride gave only $0.18 \mathrm{~g}$ of a solid that did not melt below $250^{\circ}$ and could not be purified, since it was insoluble in all ordinary solvents. Extraction of the combined chloroform ether layers with dil $\mathrm{HCl}$ and treatment of the acid extract with benzoyl chloride and alkali gave $0.39 \mathrm{~g}$ crude solid, m.p. $143-150^{\circ}$, which gave $0 \cdot 10 \mathrm{~g}(0.3 \%)$ benzanisidide, m.p. $158-160^{\circ}$, after recrystallization from alcohol. Evaporation of the acid-washed chloroform-ether solution gave $0.11 \mathrm{~g}(0.4 \%)$ anisamide, m.p. $164-167^{\circ}$.

In another experiment, conducted similarly with $10.4 \mathrm{~g}$ anisaldehyde, the diluted reaction mixture from which the precipitated anisamide had been filtered was separated from the benzene layer and freed of hydrogen azide by concentration in an air stream. The solution was then made basic with sodium hydroxide and filtered from a grey-brown, crystalline precipitate, wt. $0.2 \mathrm{~g}, \mathrm{~m} . \mathrm{p} .150-160^{\circ}$, and extracted with 6 portions benzene. Evaporation of the extracts left a small amount of crude, dark anisidine, m.p. $70-77^{\circ}$. A portion of the aqueous solution was then acidified, treated with 
sodium nitrite and then with sulfamic acid, and coupled to alkaline $\beta$-naphthol; a deep red-purple dye was produced, which stayed in solution while it was alkaline, but was precipitated by acid.

The crystalline material of m.p. $150-160^{\circ}$ was recrystallized from hot water and ethanol to obtain a pure sample, m.p. 201-202 dec (reported ${ }^{\circ 0}$ for 1-p-anisyl-5-aminotetrazole, m.p. 209-210 ${ }^{\circ}$, which reduced Tollens' reagent slowly when heated (Found: $\mathrm{N}, 36.29$. Calc. for $\mathrm{C}_{8} \mathrm{H}_{8} \mathrm{~N}_{3} \mathrm{O}: \mathrm{N}, 36.63 \%$ ).

${ }^{56}$ W. G. Finnegan, R. A. Henry and E. Lieber, J. Org. Chem. 18, 779 (1953). 